\title{
Review of Remote Sensing Methods to Map Coffee Production Systems
}

\author{
David A. Hunt ${ }^{1, *}$, Karyn Tabor ${ }^{1}{ }^{(\mathbb{C}}$, Jennifer H. Hewson ${ }^{1}$, Margot A. Wood ${ }^{1}{ }^{(1)}$, \\ Louis Reymondin ${ }^{2}$, Kellee Koenig ${ }^{1}{ }^{(}$, Mikaela Schmitt-Harsh ${ }^{3}$ and Forrest Follett ${ }^{4}$ \\ 1 Conservation International, 2011 Crystal Dr. \#600, Arlington, VA 22202, USA; ktabor@conservation.org (K.T.); \\ jenny.hewson@gmail.com (J.H.H.); mwood@conservation.org (M.A.W.); kkoenig@conservation.org (K.K.) \\ 2 Alliance of Biodiversity International and CIAT, Asia-Hanoi Hub, Agricultural Genetics Institute, \\ Pham Van Dong Street, Bac Tu Liem District, Hanoi 100000, Vietnam; L.Reymondin@CGIAR.ORG \\ 3 Department of Interdisciplinary Liberal Studies, James Madison University, Maury Hall, 800 S. Main Street, \\ Harrisonburg, VA 22801, USA; schmi2ml@jmu.edu \\ 4 The Sustainability Consortium, Sam M. Walton College of Business, University of Arkansas, \\ Fayetteville, AR 72701, USA; forrest.follett@sustainabilityconsortium.org \\ * Correspondence: dhunt@conservation.org
}

Received: 11 May 2020; Accepted: 18 June 2020; Published: 25 June 2020

\begin{abstract}
The coffee sector is working towards sector-wide commitments for sustainable production. Yet, knowledge of where coffee is cultivated and its environmental impact remains limited, in part due to the challenges of mapping coffee using satellite remote sensing. We recognize the urgency to capitalize on recent technological advances to improve remote sensing methods and generate more accurate, reliable, and scalable approaches to coffee mapping. In this study, we provide a systematic review of satellite-based approaches to mapping coffee extent, which produced 43 articles in the peer-reviewed and gray literature. We outline key considerations for employing effective approaches, focused on the need to balance data affordability and quality, classification complexity and accuracy, and generalizability and site-specificity. We discuss research opportunities for improved approaches by leveraging the recent expansion of diverse satellite sensors and constellations, optical/Synthetic Aperture Radar data fusion approaches, and advances in cloud computing and deep learning algorithms. We highlight the need for differentiating between production systems and the need for research in important coffee-growing geographies. By reviewing the range of techniques successfully used to map coffee extent, we provide technical recommendations and future directions to enable accurate and scalable coffee maps.
\end{abstract}

Keywords: coffee; remote sensing; agriculture; agroforestry; production system; mapping; land cover; land use; Landsat; Sentinel

\section{Introduction}

Coffee is an important globally traded commodity, crucial to the economies of many tropical countries, and has the capacity to either positively or negatively impact forest cover, biodiversity, and human wellbeing. Consumers drink over 400 billion cups of coffee each year, underpinning a global industry worth over 100 billion USD [1-3]. Given its importance as a global commodity as well as its potential environmental impacts, there are important questions surrounding the global impact of the sector on land use and change, including how coffee production affects the regrowth, maintenance, or clearance of tropical forests. Answering these questions will help inform sustainable coffee production practices aimed to be both environmentally beneficial and socially responsible as well as profitable for producers today and in the future. More specifically, such practices aim to 
improve the livelihoods of coffee farm workers and their families, increase the productivity of existing coffee production areas, and prevent either the clearing of high-conservation-value forests or the depleting of other natural resources [4]. Many stakeholders, including coffee traders, roasters, retailers, and governments, are also dependent on information related to coffee landscape dynamics and the extent of regional coffee production in order to ensure that sourcing and investment decisions are robust and directly contribute to zero-deforestation commitments (e.g., Refs. [5,6]), including those embedded in certification and verification programs within the Sustainable Coffee Challenge [4].

Some research has contributed to the need to understand the various landscape dynamics affected by coffee production. Schmitt-Harsh [7] suggests that coffee expansion, driven in part by expanding markets, may be tied to forest loss. Other research indicates that certain types of coffee production systems, such as shade cover systems, are associated with forest reclamation and regrowth [8]. Research in Mexico and Indonesia, for example, reveals that agroforestry practices can relieve pressures on forests by meeting local needs through farm and community tree resources [9,10]. Planted shade trees commonly provide coffee growers with fruit, nut, and timber products that can be used for household consumption or sale on local markets, thus potentially reducing the demand for forest products. Such research is limited, however, and the complete picture of the global interrelatedness of coffee production and forest cover change remains unclear. To further understand these relationships, researchers need comprehensive and accurate national- or global-scale coffee maps. These, in turn, depend on the development of scalable, replicable, and affordable approaches to coffee mapping.

The lack of successful, widespread coffee extent maps to-date has hindered a complete understanding of coffee's full environmental impact. To guide future coffee mapping and coffee sustainability research, we conducted a systematic review of existing approaches to mapping coffee using remote sensing in a diverse range of production systems varying in size and shade characteristics. First, we provide a brief overview of coffee systems. Next, we analyze different methodological approaches to landscape, sensor, and scalar dynamics as well as relative accuracy, replicability, scalability, and rigor based on a review of 43 articles from the mid-2000s onward. These articles utilize a range of recent innovations in data accessibility, cloud computing, and algorithmic development to more accurately map coffee systems. Our results are guidelines for using these methods and their current limitations and recommendations for further research given the rapid development of satellite sensor technologies and data accessibility. Through this review, we aim to provide technical recommendations to enable accurate and scalable coffee maps that underpin sector-wide measures of sustainability.

\subsection{Review of Coffee Characteristics and Systems}

Coffee originated as a wild crop in Ethiopia and has since expanded to become a globally traded and consumed commodity. Today, coffee is grown in approximately 70 countries throughout the tropics, in a region referred to as "The Bean Belt" [11,12]. Most coffee is produced on relatively small farms in areas with rugged terrain [13]. In fact, $70 \%$ of coffee is produced by smallholder farmers who depend on coffee production for their livelihoods and are extremely vulnerable to variations in production due to climate change [14,15]. Despite the competing land-use pressures and threats to production from climate change, the coffee industry continues to grow and represents a very important economic opportunity for many countries (Table 1).

Two major commercial varieties, Coffea arabica and C. robusta, dominate the coffee market. Other, less viable varieties, such as $\mathrm{C}$. liberica, represent a small portion of the market. While arabica beans comprise approximately $70 \%$ of the global market and are generally considered a higher quality coffee bean, arabica coffee trees are smaller and less productive compared to robusta coffee trees [17], they must be grown at high altitudes, and require mild temperatures and high rainfall. Conversely, robusta coffee trees, the beans of which account for about $30 \%$ of the global market, are more tolerant of a broader range of climates and elevations and have proven more resistant to diseases and parasites $[12,17,18]$. 
Table 1. Statistics on the top ten coffee-producing countries ranked by coffee production. Data collected from the Food and Agriculture Organization of the United Nations [16].

\begin{tabular}{cccccc}
\hline Rank & Country & $\begin{array}{c}\text { Coffee } \\
\text { Production } \\
\mathbf{2 0 1 7} \text { (tons) }\end{array}$ & $\begin{array}{c}\text { Area } \\
\text { Harvested 2017 } \\
\text { (ha) }\end{array}$ & $\begin{array}{c}\text { Export Value } \\
\text { of Coffee } \\
\text { Products, 2017 }\end{array}$ & $\begin{array}{c}\text { Percent of Crop and } \\
\text { Livestock Product } \\
\text { Exports by Value, 2017 }\end{array}$ \\
\hline 1 & Brazil & $2,684,508$ & $1,802,417$ & $\$ 5.27$ billion & $6.62 \%$ \\
2 & Vietnam & $1,542,398$ & 605,178 & $\$ 3.50$ billion & $15.9 \%$ \\
3 & Colombia & 760,209 & 799,046 & $\$ 2.81$ billion & $39.5 \%$ \\
4 & Indonesia & 668,677 & $1,253,796$ & $\$ 1.66$ billion & $4.22 \%$ \\
5 & Honduras & 473,718 & 434,312 & $\$ 1.29$ billion & $48.8 \%$ \\
6 & Ethiopia & 467,679 & 694,179 & $\$ 955$ million & $44.0 \%$ \\
7 & Peru & 337,330 & 424,129 & $\$ 710$ million & $13.5 \%$ \\
8 & India & 312,000 & 449,357 & $\$ 968$ million & $2.86 \%$ \\
9 & Guatemala & 246,319 & 281,841 & $\$ 749$ million & $14.1 \%$ \\
10 & Uganda & 209,421 & 379,108 & $\$ 555$ million & $34.8 \%$ \\
\hline
\end{tabular}

Arabica and robusta are both grown in a range of production systems throughout the globe. These production systems range from growing the crop under canopies in shaded agroforestry systems containing different levels of shade and canopy structures to large monoculture sun systems that are similar to other intensive row cropping production systems. Historically, farmers cultivated coffee in shaded systems to mimic the natural forest growing conditions of coffee plants. The complexity of the canopy and associated vegetation in shaded systems typically contain high levels of biodiversity (for example, Philpott et al. [19] found that some shade systems had greater than or equal ant and bird richness as nearby forests) and serve as valuable areas for the provision of ecosystem services, such as carbon sequestration and climate change mitigation [9,14,19-25]. This is particularly true where such agroforestry systems are supported by adjacent forest ecosystems [26].

In recent decades, farmers have increasingly converted shaded systems to large-scale, unshaded monoculture systems [27]. While this shift in production systems can be traced to large-scale agronomic policies and market restructuring, the impact of these forces on coffee growing practices differs across regional landscapes, with trends of widespread shade tree removal more prevalent in some countries (e.g., Colombia, Costa Rica) and little to no shade tree removal in others (e.g., Guatemala, Nicaragua) [14]. According to Jha et al. [27], as of 2010, over $40 \%$ of coffee was produced in unshaded systems. Farmers have pursued unshaded monoculture systems for two main reasons. First, removing the shaded canopies reduces moisture that can sometimes, in excessively wet conditions, lead to a devasting fungal disease called coffee leaf rust. Second, monoculture production allows for increased coffee plant density and therefore increased total crop yield, thus enabling cost-effective farming practices $[7,14]$. However, unshaded monocultural production can substantially reduce biodiversity and the carbon sequestration potential evident in shaded systems [19,28-30]. Furthermore, the biodiversity supported by coffee production and surrounding habitats is generally lower in unshaded systems, and monoculture production has also been associated with a weaker response to pest outbreaks and increased pathogen transmission [22,31,32]. In addition, the lack of mature and diverse vegetation and increased amount of exposed soil, a characteristic of monoculture systems, can lead to erosion, further decreasing the resilience and nutrient uptake in these systems [33].

Coinciding with the transition to unshaded monoculture coffee systems has been a diversification of canopy structures and management styles within shaded coffee systems. These different agroforestry systems have significant variations in terms of the provision of ecosystem services and environmental impacts [14]. Researchers often describe four different typical shaded coffee systems, varying in vertical and compositional diversity of shade $[19,34]$. These systems include understory rustic polyculture, traditional polyculture, commercial polyculture, and shaded monoculture (see Figure 1 from Moguel and Toledo [34]). Rustic polyculture systems are characterized by an intact forest canopy and minimal understory alteration—only enough to grow coffee plants successfully. In traditional polyculture 
systems, farmers maintain the integrity of the canopy but replace the entire understory with coffee and other shade-tolerant plants. In commercial polyculture systems, farmers remove both the canopy and understory, replacing the understory with coffee and the canopy with smaller trees that provide minimal shade but offer a commercial value. Finally, shaded monoculture, considered a modern shaded system, is created by removing both the canopy and understory and planting a leguminous canopy almost exclusively to provide shade for the coffee below [34,35]. While these systems categorize general, shaded management practices based on canopy and understory density, they do not represent an exhaustive list of the possible production systems throughout the world. For example, Moreira et al. [36] discuss the diversity of systems in Brazil, reporting that they exist with and without irrigation, with and without windbreaks, and with crops of different ages, areas, spacing, and varieties. For this study, we specifically focused on the distinctions captured by Moguel and Toledo [34] to highlight the diversity in vegetation structure.

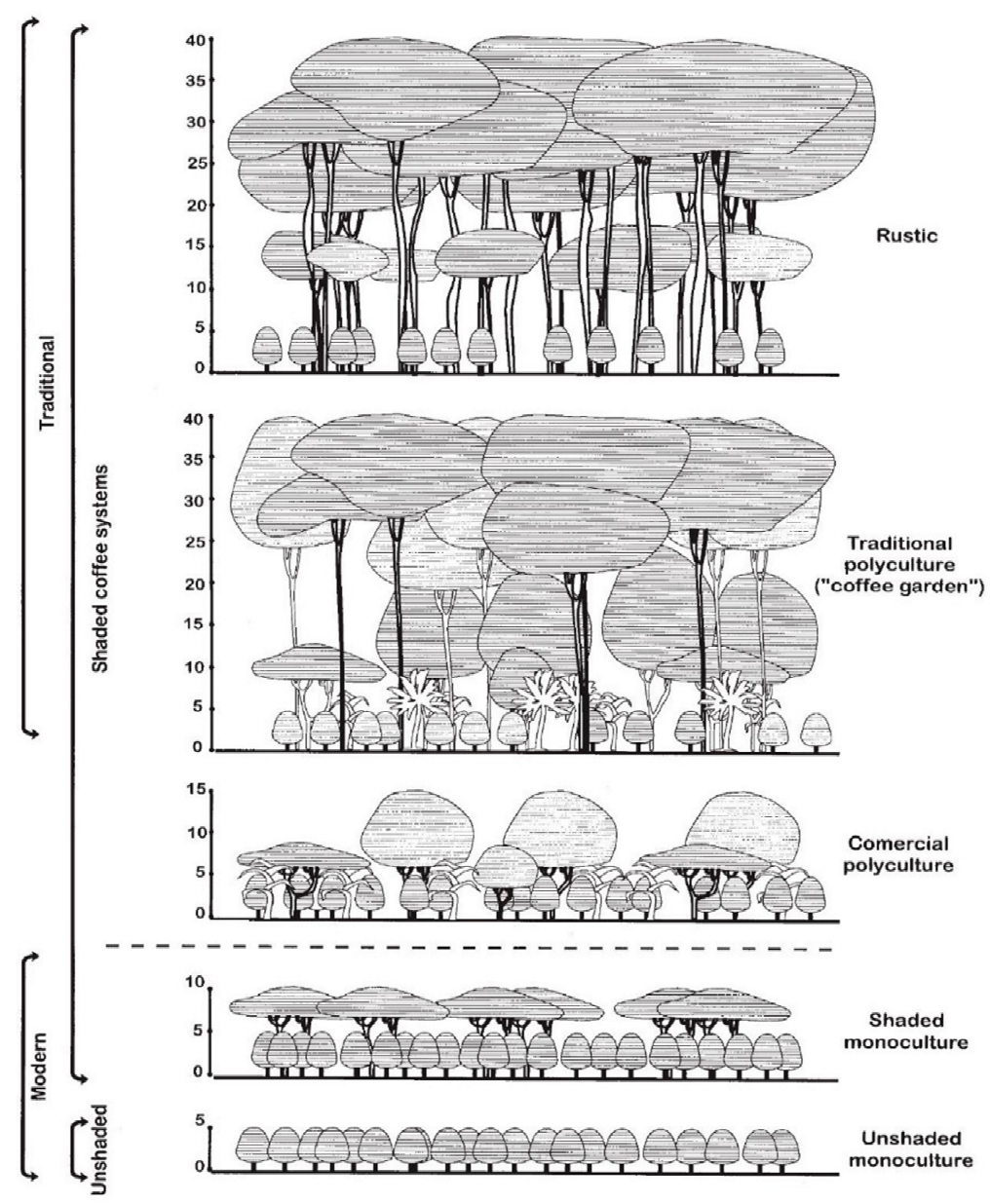

Figure 1. The figure from Moguel and Toledo [34] illustrates the canopy structure of five common coffee production systems, including four shaded coffee systems (shaded monoculture, commercial polyculture, traditional polyculture, and rustic) and unshaded monoculture.

While each system has both advantages and disadvantages in terms of productivity, management intensity, and environmental impacts, the suitability of a given system varies based on landscape characteristics. The degree of shade that is suitable for a coffee farm depends on many factors, including precipitation, annual temperature fluctuations, soil conditions, farm size, and social and institutional relations, including land tenure circumstances, relative support for smallholder agricultural production, and local knowledge [37-39]. Several coalitions, scientists, and practitioners are developing tools and 
resources to guide best practices for achieving coffee sustainability within the social and ecological context of coffee production landscapes.

\subsection{Using Remote Sensing to Map Coffee}

Remote sensing represents the most feasible approach to scalable, replicable, and affordable land cover and land use change (LCLUC) mapping. The most accessible satellite data for LCLUC mapping are from the U.S. Geological Survey's Landsat program due to the sensor's specific design for natural resource mapping, the longevity of the Landsat mission dating back to 1972, and the free release of Landsat imagery $[40,41]$. The Landsat sensor is optimized for mapping and monitoring land cover at the landscape-scale and is successfully applied to forest, non-forest, and agricultural LCLUC [42]. However, to date, the published literature on mapping coffee production areas and quantifying associated LCLUC has been limited. This is due in part to the complexity and variety of coffee production systems in addition to limitations of cost-effective, accessible satellite data. Coffee is mostly grown on small plots in heterogeneous landscapes, at relatively higher elevations in complex topographies [43-46]. Coffee is also spectrally similar to multiple other woody cover types and is often obscured from the view of most satellites by an overstory canopy, and, therefore, it is commonly confused in existing remote sensing classification approaches with other crops and land cover types [7,43,47]. For example, not only are some shaded coffee systems spectrally confused with primary and secondary forests $[43,45,46]$, but younger unshaded coffee systems can be confused with pastures and other unshaded crops [44]. Additionally, the spectral signature of coffee plants changes with age and throughout its phenological cycle (the phenological cycle of coffee lasts for two years, unlike many other crops, which complete their reproductive cycle in one year) as well as during coffee rust outbreaks [44,48]. Persistent cloud cover and steep topography in many tropical coffee-growing regions further compound mapping challenges by creating issues with image interpretation. These characteristics reduce the accuracy of coffee mapping using moderate-resolution optical satellite data, such as Landsat. This is problematic as such data underpin the most accessible, affordable, and reliable methods for LCLUC mapping.

Fortunately, recent advances in satellite technologies and investment in a range of sensors and satellite constellations by governments and the private sector are helping overcome tradeoffs in spectral, temporal, and spatial resolution $[49,50]$. For this paper, we refer to high spatial resolution data as less than $5 \mathrm{~m}$, moderate spatial resolution as between $5 \mathrm{~m}$ and $60 \mathrm{~m}$, and coarse resolution as greater than $60 \mathrm{~m}$. The increased coverage and availability of data from Synthetic Aperture Radar (SAR) sensors since 2015, mainly as a result of the European Space Agency's Copernicus Programme, can help address the limitations presented by optical imagery in cloudy regions [50]. SAR sensors utilize the microwave portion of the electromagnetic spectrum, actively emitting energy pulses to the earth and measuring the returned backscatter. Unlike optical sensors, energy in the longer wavelengths used by SAR sensors can penetrate clouds; thus SAR instruments can complement optical sensors in cloudy areas and fill data-gaps due to cloud cover [50]. This is particularly relevant for coffee mapping, given the majority of coffee cultivation occurs in persistently cloudy tropical regions. Another advance has been the number of high resolution optical sensors, providing reliable, high spatial resolution imagery without compromising temporal frequency; this is particularly useful considering the small area of most coffee farms. Planet Labs, for example, currently has a constellation of over 140 Dove satellites in orbit able to capture high resolution imagery $(3.7 \mathrm{~m})$ with daily global coverage [51]. Moderate resolution satellite constellations, such as the integration of $30 \mathrm{~m}$ Landsat with $10 \mathrm{~m}$, "Landsat-like" Sentinel-2A and $2 \mathrm{~B}$ instruments from the Copernicus Programme provide global, multi-spectral imagery every 2.9 days [52]. With these recent advances in remote sensing technologies and data availability, combined with the increased demand for sustainable coffee production, we see the opportunity to capitalize on these technological advances and address sector-wide demands to improve remote sensing methods for more accurate, reliable, and scalable approaches to coffee mapping. 


\section{Methods}

To address the need for widespread coffee extent maps, we conducted a systematic literature review of available research on coffee mapping and classification using remote sensing methodologies. We modeled our framework on Pullin and Stewart [53], who outlined a three-stage best practice approach for developing and conducting a systematic review in the fields of conservation and environmental management. We operationalized the three stages, which included planning the review, conducting the review, and reporting the review, as described below.

\subsection{Planning the Review}

In the first stage- " planning the review"-we developed the concept for this literature review with partner organizations (ranging from academia to corporations to research non-governmental organizations) from the Sustainable Coffee Challenge [4]. We identified the need for this review through several discussions on the topic of mapping coffee production areas and the desire to measure and track sustainability goals. This guided us in developing our central research objective: determining the most effective remote sensing method for mapping coffee extent across varied geographic settings and landscape characteristics. Due to the diversity of production systems and landscape types, we aimed to capture each of the five general production systems outlined in Moguel and Toledo [34] in the literature review. This would ensure widespread applicability in different geographies and increase the likelihood of the implementation of our recommended methods. We also chose to include methods from 2010 onwards to best capture approaches that employ the newest satellite sensor technologies (e.g., the availability of the RapidEye constellation beginning in 2009, the launch of Landsat 8 in 2013, and the launches of Sentinel-1A in 2014, Sentinel-2A in 2015, Sentinel-1B in 2016, and Sentinel-2B in 2017) and advances in computing capacity, such as the increased use of cloud computing (e.g., Google Earth Engine) and deep learning.

\subsection{Conducting the Review}

We chose to use Google Scholar rather than subscription platforms such as Web of Science for our systematic search. We did this to ensure our approach would be broadly reproducible and avoid access limitations. However, to further develop our database, we supplemented our systematic search within Google Scholar with a purposive search conducted with coffee mapping experts. We also expanded our search terms as we proceeded, reflecting initial limitations in gathering sufficient relevant literature.

We began by searching Google Scholar for all articles since 2010 using the search terms in Table 2. We divided these terms into three categories and combined terms from each category into the search phrases entered in Google Scholar. The results of the searches were then reviewed manually by title to identify their relevance to our research aim. If the title proved relevant, we then reviewed the abstract to screen for additional articles that fulfilled the criteria listed above. Given the scarcity of resulting articles, we also pursued three additional approaches to supplement our article database. First, we systematically reviewed all resulting articles for additional references that matched our search criteria. Second, we expanded our search to included peer-reviewed publications, grey literature, and reports from the mid-2000s onward, as well as approaches for mapping cacao. We selected cacao based on its similarities to coffee vis-à-vis mapping challenges, the similarity of geographies and countries in which cacao and coffee are grown [54], and the diversity of smallholder production modalities [13]. Third, we presented our initial results at an expert workshop (described in Section 2.3) to gather feedback and additional references.

Our Google Scholar search yielded 23 articles, while our purposive sampling approach produced 19 articles, 11 of which came from experts from the workshop. We also received one additional paper during the peer review process. Most articles were in English, though we did receive three studies in Portuguese and two studies in Spanish. We carefully and systematically reviewed each article to understand the mapping approach and implemented methods. As we reviewed the articles, 
we categorized the relevant information into three matrices (Tables S1-S3 in the Supplementary Materials) to capture the classification method, the validation method, and the information related to choosing the best method in future research. We then aggregated the information in the matrices to identify common themes, including the prevalence of various classification approaches, the number of studies that used certain sensors, or gaps in the literature.

Table 2. Search terms used in Google Scholar to find studies that examine effective remote sensing methods for mapping coffee extent.

\begin{tabular}{ccc}
\hline Coffee & Remote Sensing & Geography \\
\hline coffee & remote sensing & mapping \\
agroforestry & satellite & tropics \\
shade-coffee & Sentinel-1 & global \\
sun-coffee & Sentinel-2 & Indonesia \\
polyculture & MODIS & Colombia \\
monoculture & SAR & Brazil \\
Arabica & Landsat & Vietnam \\
Robusta & optical & Ethiopia \\
& high resolution & \\
\hline
\end{tabular}

\subsection{Reporting Results}

We presented a first draft of the coffee mapping literature review during an experts' workshop hosted by Conservation International in August 2019. The Coffee and Forest Conservation Workshop included participants from the consortium partners and other experts in the field. These twenty participants represented the International Center for Tropical Agriculture, the International Coffee Organization, the Sustainability Consortium, the Rainforest Alliance, and James Madison University. During the workshop, we sought expert consultation on gaps, missing literature, and any additional relevant comments. Workshop participants provided 11 additional papers on coffee mapping that we did not encounter in our initial search, along with studies of other crops and forest composition classification methods that complemented our findings. We reviewed these additional articles to determine their final inclusion in the study. Other feedback from the workshop, such as missing content, was also incorporated into this final review.

\section{Results}

Our systematic literature search yielded 43 peer-reviewed publications and reports. We categorized each article according to the remote sensing classification approach used in the study and identified six dominant classification approaches: spectral pixel-based, spectral sub-pixel-based, texture-based, data fusion, object-based, and hybrid. Fourteen studies applied multiple classification approaches to compare mapping outcomes. For studies that used multiple approaches in different classification models, we categorized them based on the primary approach identified in the study. Studies that incorporated multiple methods into the same classification model were considered hybrid approaches. We also captured the accuracy assessment methods used, as this represents a crucial step in understanding the validity of the resulting product. Supplementary Tables S1-S3 provide an overview of the 43 articles, including the geographic location of the study, the sensor(s) utilized, the classification approach(es), the accuracy of the product, and the validation method.

\subsection{Spectral Pixel-Based Approaches}

Sixteen articles utilized spectral pixel-based methods with optical imagery exclusively (IKONOS-2, Landsat, Moderate Resolution Imaging Spectroradiometer (MODIS), Sentinel-2, Satellite Pour l'Observation de la Terre (SPOT), RapidEye), while an additional thirteen used spectral pixel-based approaches in conjunction with other methods. Such methods classify pixels in an image into land cover 
classes based on a given pixel's similarity to the spectral signature of the land cover types in the study area. Many of these articles used training datasets collected in the field and implemented a range of classifiers including: a hybrid approach [55], maximum likelihood [7,45,56,57], random forest [58-60], support vector machine [61], and convolutional neural networks [61]. Some spectral pixel-based approaches used only the bands present in the imagery. For example, Ramirez et al. [62] compared Landsat bands 3, 4, and 5 with the IKONOS-2 panchromatic image; Sanchez-Mendez et al. [63] utilized Landsat 8 bands 2-7; Moreira et al. [64] used bands 3, 4, and 5 from Landsat Thematic Mapper (TM) and Enhanced Thematic Mapper Plus (ETM+), finding them the most effective at differentiating coffee from other scene targets; and Schmitt-Harsh [7] used bands 1-7 from Landsat TM. Multiple studies also incorporated band ratios and indices to extract more information from the data, most commonly the normalized difference vegetation index (NDVI). NDVI is frequently used to map vegetation productivity [44,45,57,60,63,65-67]. Numerous other spectral indices we reviewed included the enhanced vegetation index (EVI) [12], land surface water index (LSWI) [57,65], normalized difference red edge index (NDRE) [66], and moisture stress index (MSI) [66], among others. Other methodological approaches also utilized additional indices, located in Supplementary Table S1. Some approaches used principal component analysis techniques, such as Tasseled Cap transformations, instead of utilizing simple band ratios. For example, Kelley et al. [60] and Tutu Benefoh et al. [57] used greenness, brightness, and wetness bands produced by a Tasseled Cap transformation.

While spectral pixel-based methods can be less complex to implement when employed alone, they can be limited by cloud cover and are potentially unable to adequately incorporate coffee heterogeneity into models [68]. Therefore, a few studies added ancillary data beyond spectral values or functions to improve mapping accuracy. Martinez-Verduzco et al. [56] found that incorporating data from community-based mapping into a spectral analysis increased the accuracy by $1.6 \%$ (from $73 \%$ to $74.6 \%$ ). While they did not deem this modest increase statistically significant, consulting local experts on community mapping did reduce the time and resources of the study, a potentially valuable lesson for future classifications in rural areas with limited funds. Kelley et al. [60] also included three elevation products (elevation, slope, and aspect) and meteorological values in their study. Each of their spectral composite images included a surface temperature band as well as an additional layer with a time-lagged correlation of precipitation and later shifts of NDVI. They found that including elevation data increased the overall accuracy of their non-seasonal model by $20.1 \%$ (to $85.7 \%$ ) and their seasonal model by $7.8 \%$ (to $89.5 \%$ ). The addition of the precipitation correlation to the seasonal model (with elevation) gave them a further bump of $1 \%$ to $90.5 \%$ overall accuracy.

\subsection{Spectral Sub-Pixel Approaches}

Spectral sub-pixel approaches are often applied to mapping applications with moderate- and low-resolution imagery (Landsat and MODIS) in complex, heterogenous landscapes to overcome limitations due to spatial resolution. Sub-pixel-based approaches estimate the relative proportions of constituents in a landscape that are represented by a single pixel. The constituents, referred to as "endmembers", are distinct sub-pixel classes characterized by the reflectance measures of pure surface elements, such as green vegetation, bare ground, and water. Pixels contain fractions, or fractional endmembers, of each class. For example, a pixel estimated to contain 5\% bare soil, $25 \%$ shade, and $70 \%$ green vegetation may represent a shaded coffee system, whereas a pixel containing 30\% bare soil, $10 \%$ shade, and $60 \%$ green vegetation may represent a sun-grown system. Schmitt-Harsh et al. [69] used spectral mixture analysis, with shade, soil, and green vegetation as endmembers. They used aerial photographs to train a maximum likelihood classifier for four models with different combinations of bands, fraction images, and thermal images. The coffee agroforestry class ranged from 67-90\% for user accuracy and 81-92\% for producer accuracy across the four models. Bispo et al. [70] used spectral linear mixing to derive fraction images (soil, coffee, and water/shade) from MODIS imagery, which they used as input data in a Support Vector Machine classifier. The efficacy of this approach was limited, however, as the highest overall accuracy was $67 \%$. Spectral mixture analysis has successfully been used to classify 
different stages of successional forest [71] and detect forest cover changes [72,73], demonstrating its efficacy in heterogeneous landscapes where coffee is typically grown. However, spectral sub-pixel approaches, while better at capturing landscape heterogeneity than spectral pixel-based approaches, are often still limited by cloud cover and are more time-intensive than pixel-based approaches, requiring more technical training and computing power to complete the analyses. A full assessment of sub-pixel-based approaches to the coffee sector is challenging, given that few scholars have pursued this approach.

\subsection{Texture-Based Approaches}

Classifying imagery based on the texture of a surface, i.e., surface roughness, is commonly applied to high-resolution imagery and with SAR imagery backscatter. For this paper, we reviewed three studies that exclusively employed a texture-based analysis [74-76]. Lelong and Thong-Chane [74] used Ikonos and Quickbird panchromatic images to classify various tropical crops, including two coffee classes. To avoid the issues associated with distinguishing the spectral signatures of different shade systems from the surrounding forest, they calculated height textural indices (mean, variance, homogeneity, contrast, dissimilarity, entropy, second moment, and correlation) on the two images for windows from 3 to 9 pixels and using a maximum likelihood classifier. The authors did not report an accuracy assessment with this study, however, so the efficacy of this method remains uncertain. Dostalova et al. [75] used a combination of the VV and VH (vertical and horizontal) polarization backscatter from Sentinel-1 to classify forests. They performed a forest classification using both a thresholding method based on the Otsu algorithm (an automated thresholding method for image segmentation presented in Otsu [77]) and k-means clustering (a statistical method to identify data cluster centers presented in Hartigan and Wong [78]) to obtain overall accuracies of $92 \%$ and $88 \%$, respectively. Silva et al. [76] used SAR data to specifically map coffee. They used single polarization, combinations of two and three polarizations, and fully polarimetric data to classify imagery in Brazil collected by an airborne SAR-R99B sensor. Accuracy for this classification varied widely depending on the polarization used: single polarization achieved $38.4-56.4 \%$ overall accuracy, while the fully polarimetric data achieved $96.6-97.6 \%$ overall accuracy. Given the success of the fully polarimetric data in Silva et al. [76], researchers should continue to explore the potential utility of SAR data to map coffee.

\subsection{Data Fusion Approaches}

Several studies employed a data fusion approach by combining data from multiple sensor types into an analysis. For example, Zhou et al. [79] used textural information from Sentinel-1 imagery and spectral information from Landsat 8 to create ten different models (including combinations of strict radar and radar/multispectral fusion) to map winter wheat with a maximum overall accuracy of 99.8\%. Lu et al. [80] utilized Landsat ETM+ and RADARSAT-1 data fusion to classify landcover, including coffee plantations and an agroforestry class. These methods produced a moderately low overall accuracy, however, with the most successful model achieving an accuracy of $71.0 \%$. Lu et al. [46] performed an analysis of both the comparison and data fusion of Landsat TM imagery, SPOT imagery, and textural images derived from SPOT imagery calculated using eight texture measures and nine sizes of moving windows. These models also performed relatively poorly, with a maximum overall accuracy of $61.8 \%$. Liu et al. [81] used Sentinel-1, Sentinel-2, Landsat 8, and a digital elevation model (DEM) to map forest type and obtained a maximum accuracy of $82.8 \%$. Numbisi et al. [82] used textural information from Sentinel-1 imagery and spectral information from RapidEye to create eight models (multispectral, radar, and sensor fusion) to map cacao, with an accuracy ranging from $78.8-88.1 \%$. Fagan et al. [83] used a multispectral and hyperspectral data fusion process with Landsat and 2005 Hymap, respectively, to map forest type and tree plantation by species composition in Costa Rica. Utilizing both multispectral and hyperspectral data increased the overall accuracy of the model compared to hyperspectral data-only models, with an improvement from $83.5 \%$ to $88.5 \%$. 


\subsection{Object-Based Approaches}

In an object-based approach, pixels in an image are segmented into objects based on spectral similarity or external variables (e.g., land governance) to produce a map classification. Researchers commonly apply this approach to high-resolution imagery. Lelong [84] and Vieira et al. [85], for example, used Quickbird and Landsat imagery respectively, to perform a computer-assisted photointerpretation to manually classify each individual plot in their study area based on their similarity to predetermined patterns of land use. While the accuracy of these studies was unreported, Lelong [84] required $700 \mathrm{~h}$ to complete this process, limiting its potential as a scalable, replicable method. Alternatively, Dos Santos et al. [86] studied the effect the scale of an object has on the accuracy of the classification of SPOT imagery using two classifiers, Support Vector Machine (SVM) and Radial Basis Function (RBF), and boost-classifiers by building a linear combination of these classifiers (based on the AdaBoost algorithm proposed by Schapire [87]). They concluded that coarser-scale objects had an accuracy of up to three percent greater and lower training times than the finer-scale objects and that the boost-classifiers improved accuracy over the RBF classifier by five percent. Gaertner et al. [88] compared the accuracy of a spectral pixel-based approach using a maximum likelihood classifier with an object-based support vector machine model to map coffee fields in Hawaii. The object-based method was the more accurate approach to map coffee, with a 76\% producer accuracy and a $94 \%$ user accuracy for the object-based model compared to a $72 \%$ producer accuracy and a $69 \%$ user accuracy with the pixel-based model. Bolanos [47] performed a similar analysis comparing pixel-based methods to object-based methods. This study also found object-based analyses to be more successful than pixel-based methods, with a $3 \%$ overall accuracy improvement of the product and a 17\% overall accuracy increase for the coffee class. Lastly, as in pixel-based analysis, ancillary data was also used to improve the accuracy of object-based classifications. By adding data such as elevation information from a DEM and a previously created national forest cover map to their coffee mapping methodology, Mukashema et al. [89] improved their overall classification accuracy from $50 \%$ to $87.6 \%$.

\subsection{Hybrid Approaches}

Other, generally more complex, approaches used multiple sensors and/or approaches within the same classification model to map coffee aiming to leverage the strengths of different methods. For example, Alves et al. [90] used tone, color, texture, shape, size, pattern, and shade as elements to classify coffee and four other land cover classes using visual interpretation. While the exact method they used was not fully documented, we considered this a hybrid approach. Gomez et al. [91] performed an analysis technique that combined a pixel-based approach with a texture-based approach. This study used a $3 \times 3$ pixel window to map tree canopies using a multi-layer perceptron and divided the canopies based on heterogeneity and size using NDVI, VIN, and 48 textural attributes to identify suitable areas for coffee inter-specific hybridization. Widayati et al. [92] utilized an integrated pixel-based analysis and object-based approach to create extent maps of various coffee production systems in Sumberjaya, Lampung Province, Indonesia, with an overall accuracy of $84.5 \%$, and Xiong et al. [93] utilized pixel-based analysis and an object-based approach to create a cropland extent map of the African continent, with an overall accuracy of 94.5\%. Kawakubo and Machado [68] created a model using both object-based and subpixel-based analyses. They also used data mining techniques to create objects based on spectral metrics from a spectral mixture analysis (using dark green vegetation and non-photosynthetic vegetation endmembers) and a root mean square error fraction image. Their approach effectively distinguished coffee classes from non-coffee classes, with an accuracy greater than $70 \%$. Other hybrid examples include the studies by Moreira et al. [36], which involved combining a spectral pixel-based method and photointerpretation, and Dos Santos et al. [94], which incorporated textural analysis in conjunction with spectral pixel analysis. 


\subsection{Accuracy Assessment}

Map validation is a crucial component of any remote sensing classification methodology, as it assesses the success and reliability of the product and subsequent analysis. In this section, we describe the validation methods used in the literature to determine the accuracy of classification results. Due to the different approaches used for validation (e.g., considerable heterogeneity in the number of classes mapped, the validation sampling strategies, and sample size), the accuracy results cannot be directly compared across studies. Instead, we summarize studies by key characteristics of an accuracy assessment, specifically: sampling design, reference data, and analysis as outlined by Olofsson et al. [95]. Supplementary Table S3 provides a complete list of the validation methods used in the 43 papers examined in this review.

Sampling design or selecting the types of validation data and the number of validation points for the assessment, is the first step of an accuracy assessment. The number of validation data points used for each study in our review varied widely. Ortega-Huerta et al. [55] used only 43 data points in total (10 data points for the coffee class), whereas Xiong et al. [93] used 1754 data points. It is important to note, however, that the size of the study areas in these two classifications were drastically different. Ortega-Huerta et al. [55] classified a small area in southwestern El Salvador, while Xiong et al. [93] classified the entire African continent. This review identified three main sampling strategies in the literature. First, 13 studies performed sampling using their classified land cover maps. Of these studies, 5 used a random sampling method, 5 used a stratified sampling method, 2 papers targeted points based on areas deemed to be inaccurate, and 1 paper did not use sample points, but instead performed an accuracy assessment of the entire referenced classification. Olofsson et al. [95] recommend a stratified sampling to limit biases caused by less prevalent land cover classes. An additional 16 studies used a class occurrences dataset collected before the mapping exercise and split the dataset into a training dataset and a validation dataset. Finally, 7 studies used separate independent data sources for both the calibration and validation datasets.

Response design is the process of determining the reference land cover class in each respective sampling unit [95]. All studies compared classification results to an independent reference dataset to obtain context for the validity of the land cover product. In 4 studies, the reference classes were collected solely through the interpretation of high-resolution imagery. Another 12 studies used data collected in the field, while the final 18 studies used a combination of high-resolution imagery interpretation, field visits, and/or previously collected data. For example, Mukashema et al. [89] compared remote sensing results to both data collected in the field and survey data at the district level.

The validation analysis specifies the metrics used to present the accuracy of the product [95]. Our review revealed that researchers employed multiple measures of accuracy. The Kappa index of agreement [96], presented by 28 papers, aims to assess map accuracy by accounting for the random distribution of mapped areas of each class as well as the random distribution of class geolocation. In addition, 30 studies reported a confusion matrix [97] and 31 studies reported overall accuracy. The minimum overall accuracy reported was 18.6\% [67], and the maximum was 99.8\% [79]. For a complete set of overall, producer's, and user's accuracies, see Supplementary Table S2. Four of the reviewed studies presented an estimation of uncertainty of validation metrics (Supplementary Table S3).

\section{Discussion}

In this section, we discuss the advantages and disadvantages of methodological approaches in the literature in addressing the common challenges of mapping coffee. We present considerations and recommendations to guide the process for choosing the best approaches for mapping coffee production systems. We also highlight opportunities for future research to address the urgent needs regarding where and how the coffee sector can invest to achieve sustainable production. 


\subsection{Approaches to Overcome Coffee Mapping Challenges}

Our results indicate that researchers use a variety of approaches and sensors to map coffee. Spectral pixel-based approaches using moderate resolution optical imagery were the most common methods, highlighting the utility of multispectral data for separating coffee from spectrally similar land cover in a complex landscape. The sensor used most frequently was Landsat $(30 \mathrm{~m})$, with accuracies ranging from approximately 50-95\% [7,36,45-47,55,57-60,62-66,69,71-73,79-81,83,85,93] (see Supplementary Table S1). Researchers frequently relied on indices such as NDVI, EVI, VIN, LSWI, SAVI, NDRE, and MSI to extract more information from multispectral bands to map features within their study area. Freely available multispectral data, such as Landsat 8 and Sentinel-2, have 11 and 10 bands respectively, ranging from $20 \mathrm{~nm}$ to over $200 \mathrm{~nm}$ in bandwidth. This is sufficient to provide an adequate number of bands for analysis and to calculate a range of indices to successfully map coffee extent.

Another approach to map complex coffee-growing landscapes is to capture phenological change with multi-temporal data. Coffee's two-year phenological cycle, recognized by coffee yield forecasters as an important characteristic for modeling coffee production, may also lend itself to remote sensing detection of the crop [44]. If this biennial growth cycle can be accurately captured using a remote sensing classification time series, this could increase the separability of coffee-growing areas from their surrounding environment. Ortega-Huerta et al. [55] used Landsat to perform a classification based on multi-date imagery to capture seasonal variations, even with its temporal resolution of 16 days. Researchers have also used imagery from multiple Landsat systems to increase image frequency. Kelley et al. [60] utilized 143 Landsat scenes from multiple years to effectively differentiate dry hot, rainy, and dry cool seasons. This differentiation gave a significant boost to overall accuracy $(81.7 \%$ for seasonal data) compared to a non-seasonal dataset of the same variables (65.6\%). Chemura et al. [65] used Landsat 8 imagery to track NDVI and LSWI values over time to track trends in crop growth.

While the use of Sentinel-2 to map coffee extent with spectral pixel-based approaches is currently limited in the literature, this is most likely due to its recent launch in 2015. For example, Bourgoin et al. [58] used Sentinel-2 to map land cover, including coffee extents, in Vietnam; however, the study produced an overall landscape analysis and ecological vulnerability assessment and not an analysis of the accuracy of their approach to mapp coffee. Chemura et al. [98] used Sentinel-2 to identify the level of rust outbreaks in coffee plants, Chemura et al. [99] mapped foliar nitrogen in coffee using Sentinel-2, and Xiong et al. [93] used Sentinel-2 to map cropland extents, though not specifically coffee extents. Hyperspectral sensors provide even greater spectral detail to separate coffee production systems in complex landscapes. Optical data from high spectral resolution sensors provide an increased ability to distinguish between landcover classes with similar spectral profiles, such as shaded coffee systems and forests. For example, Fagan et al. [83] used hyperspectral imagery from Hymap 2005 with 126 spectral bands, along with multispectral imagery, to successfully classify forest composition with a fusion approach. The number of fine spectral bands in hyperspectral imagery could be valuable in mapping coffee and distinguishing it from surrounding species, although its efficacy is mostly unstudied in the literature and data availability are more limited than multispectral data.

Furthermore, a handful of studies in our review applied hybrid approaches by combining several methods to separate coffee plants from spectrally similar vegetation to overcome challenges of landscape heterogeneity. Generally, these approaches introduce complex methods that are difficult for practitioners to replicate and may be overly specific to a single landscape, preventing scalability of the approach. However, we encourage innovation in this space, but also recommend researchers invest in packaging their methods in a software program or platform to increase accessibility for practitioners.

Coffee farms, particularly shaded coffee farms, typically occupy areas smaller than the minimum mapping unit of moderate or low spatial resolution remote sensing products. Therefore, researchers trying to address the issue of scale used spectral pixel-based and object-based approaches with high spatial resolution sensors. High spatial resolution data provide greater detail in each scene, which increases the likelihood of distinguishing smallholder agroforestry systems from the surrounding forest landscapes. Object-based analyses with high-resolution imagery were found to be more successful 
than spectral-pixel based analyses by comparative studies in the literature $[47,88]$. High-resolution sensors are also useful in validation methods when data collection in the field is not a viable option. Despite the success using high-resolution imagery, the costs associated with these proprietary data make its use as the primary imagery source in a scalable methodology impractical.

There are more cost-effective, scalable approaches to address the challenges related to mapping small-scale coffee farms, however. One method is to examine object-based approaches with moderate resolution sensors. Belgiu and Csillik [100] proved the utility of using object-based approaches for moderate resolution Sentinel-2 imagery for croplands. Similar studies should be performed for coffee mapping to understand the true efficacy of object-based approaches with Sentinel-2's higher resolution $(10-20 \mathrm{~m})$ compared to similar bands in $30 \mathrm{~m}$ resolution Landsat. Additional studies used sub-pixel-based approaches with moderate resolution sensors to account for coffee farms that were smaller than the minimum mapping unit. The results of these studies were variable, but Schmitt-Harsh et al. [69] were able to successfully map coffee using a sub-pixel-based approach on Landsat imagery. Radoux et al. [101] highlighted the potential for sub-pixel classification approaches to be implemented with Sentinel-2 imagery. As with object-based approaches, sub-pixel approaches to mapping coffee using Sentinel-2 imagery should be further explored.

To address the issues of cloudiness in coffee-growing landscapes, researchers have explored using data with various temporal resolutions to perform both time-series and multi-image analyses. High temporal resolutions are useful in landscapes with frequent cloud cover, as well as capturing temporal variability in the production system [44] and deforestation and degradation [73]. For example, Bernardes et al. [44] utilized the one-day to two-day revisit time of the Terra satellite's MODIS sensor to successfully study coffee yields. High spatial resolution imagery from proprietary data sources, such as RapidEye, can also have nearly daily revisit times due to larger satellite constellations and was used to map coffee [90] and cacao [82]; however, viability for use at larger scales is inhibited by the high cost of proprietary imagery. With a revisit time of only five days, Sentinel-2 could also prove a viable data source for coffee extent mapping to overcome issues of persistent cloud cover. In addition, the "virtual constellation" of Landsat and Sentinel sensors further increases the revisit rates [102].

Another strategy to overcome persistent cloud cover is to use SAR data for texture-based analysis and with fusion-based approaches. Cloud cover is an issue with optical sensors and not with SAR sensors because the longer wavelengths can penetrate clouds, so multi-image analysis with radar data is less dependent on high temporal resolution. However, studies using Sentinel-1 radar data $[75,79,81,82]$ still use multiple images to gather additional data and measure seasonal variability. Sentinel-1's twelve-day revisit time per satellite, or six days for the constellation, helps effectively create imagery time series. While we found only one study using SAR to map coffee, researchers have used SAR data to map various croplands and forest types and thus, could inform coffee mapping methodologies. SAR data could also allow researchers to study the structure of the observed vegetation, which would be useful in differentiating shaded coffee production systems from surrounding forests. However, the displacement effects of the backscatter signal together with relief shadows can limit the efficacy of SAR data in complex topographies.

Although we aimed to review literature that can successfully map different coffee-growing systems, we only found one publication that mapped five different production systems [92], and we did not find any literature focused on mapping the five production systems that we had defined to frame our review (unshaded monoculture, shaded monoculture, commercial polyculture, traditional polyculture, and rustic). One reason for the limited number of published studies on coffee mapping could be a positive publication bias, where unsuccessful studies or inaccurate maps are not published. It is also possible that more research on mapping the five coffee systems has been published in non-English journals as coffee is mostly grown in the global tropics where English is not the dominant language. Such publications would not be captured as effectively in our literature review. Despite the limited number and variety of published studies, it is nevertheless still possible to make recommendations based on our findings. 


\subsection{Considerations for Choosing the Best Method}

Analysts and practitioners should consider several factors prior to selecting a mapping approach to ensure that they are employing best practices and will have the most effective results under their respective circumstances (Box 1). We recommend considering constraints to an analysis, such as budget and complexity of the method. We advise that choosing methods already tested in a specific geographic region and for the target coffee systems is advantageous. Furthermore, establishing an accuracy assessment plan at the start of the project, rather than after the completed analysis, can help improve the robustness of validation. We describe each of these considerations in further detail below, and an overview of the information associated with each consideration for the 43 papers reviewed in this study is provided in Supplementary Table S2.

Box 1. Considerations for coffee mapping.

- $\quad$ Budget for imagery, software licensing, and validation data.

- $\quad$ Complexity of approach (i.e., processing requirements, replicability).

- Methods tested in similar geography and for target coffee system(s).

- Accuracy assessment plan.

Our recommendations emphasize freely available sources of data and low-cost methods to increase replicability and feasibility at larger scales. Minimizing costs and ensuring scalability to new geographies in the future requires free, globally available imagery such as MODIS, Landsat, Sentinel-1, and Sentinel-2. High resolution imagery that is generally proprietary, while often incredibly effective at mapping coffee accurately [88], has scenes that cover a small area and would be difficult and expensive to implement in future new studies. Although researchers have not yet adequately explored using Sentinel-2 for coffee mapping, its 10-20 m resolution bands, 5-day revisit time, and free, global coverage, along with its success mapping other crops [93] and forests [81], strongly suggests its potential for use in mapping coffee. Sentinel-1 radar data also provides an interesting option to address mapping coffee in cloudy tropical regions. These data also enable a texture-based approach to capture aspects of canopy structure, a key property for distinguishing coffee systems. A drawback to SAR data is the issue of displacement effects associated with the backscatter signal and relief shadows [103]. This could be problematic for mapping coffee in areas of complex topography such as steep slopes, particularly given the projected shifts in coffee-growing suitability to higher elevations under climate change [104].

The level of complexity of a coffee extent mapping methodology reflects the difficulty and amount of effort needed to implement it. While this measure is subjective, it is a useful metric to consider before establishing if an approach is scalable. A researcher needs to balance the complexity of the analysis by considering the amount of detail a model can capture and its accuracy. A simple model that is easily scalable may have poor results, while an overly detailed, accurate model may be so complex that it would be difficult to apply to numerous study areas. For example, the method used by Gomez et al. [91] to map individual tree canopies is complex and would be difficult to implement on a large scale. Bernardes et al. [44] tested a simpler and more scalable methodology using the NDVI and EVI MODIS products; however, using this methodology to map coffee would not produce the detail required to adequately map smallholder coffee farms. Cordero-Sancho and Sader [45] used a simple pixel-based maximum likelihood classifier with five Landsat bands, NDVI, and cos (i) (solar radiance incident angle) to achieve high producer's accuracy in distinguishing shaded and sun coffee $(91.8 \%$ and $86.2 \%)$. This method produced a low user accuracy $(61.1 \%$ and $68.4 \%)$, potentially showing that this approach does not adequately differentiate coffee systems from surrounding land cover classes. Gaertner et al. [88] discuss potential shortcomings of pixel-based maximum likelihood methods and compare this approach with an object-based image analysis, concluding that the object-based method improved overall accuracy by about $15 \%$. An object-based classification approach could be 
a promising method to map coffee extent, although its efficacy may be limited without expensive high-resolution imagery.

Other methods from the literature balance complexity and accuracy more effectively. Schmitt-Harsh et al. [69] used a pixel-based maximum likelihood classifier on Landsat TM imagery and spectral mixture analysis identifying shade, soil, and green vegetation endmembers. By incorporating the fraction images from these endmembers into the classification, along with optical and thermal bands, this study achieved a producer's accuracy of $88.6 \%$ and a user's accuracy of $89.7 \%$ for coffee agroforests. Spectral mixture analysis can be effective because it accounts for the physical processes causing the observed spectral signature and therefore incorporates mixed pixels [68]. This could be a particularly useful method as coffee is mostly grown in heterogeneous landscapes. Sensor fusion methods can also achieve high-accuracy results without overly laborious methodologies. Zhou et al. [79] used Sentinel-1 and Landsat imagery to create many different models with various levels of data fusion. By combining six Sentinel-1 images and the NDVI and the simple ratio index (SR) from one Landsat scene, this study was able to obtain a $99 \%$ accuracy using both a random forest and support vector machine classifiers. While this method was applied to map winter wheat extent and not coffee, Joshi et al. [105] reviewed numerous additional studies that successfully utilized optical and radar data fusion for diverse land use classifications. Researchers should explore similar methods as viable options for mapping coffee extent in the future.

A successful methodology should also be developed based on the climatic and edaphic conditions of the region under investigation. Ideally, this would involve studying previously implemented methodologies from similar locations, although the dearth of existing literature makes this challenging. Specific approaches can still be tailored to geographical considerations, however. For example, Kelley et al. [60] created seasonal composite images for the dry hot, rainy, and dry cool seasons of the central highlands of Nicaragua. While this added complexity to the method, it also significantly increased the overall accuracy over the non-seasonal composite by $16.1 \%$. This method could be particularly useful for shade-coffee, as the authors cite the seasonal data's ability to capture "intra-annual phenological variation across common woody and non-woody land cover classes" as crucial to the model's classification accuracy and the ability to distinguish coffee from other surrounding forest classes. Incorporating precipitation and elevation, slope, and aspect data from the region increased the overall accuracy an additional 8.8\%. Additional climatic elements, such as local cloud cover, should also be considered. Image time series could allow researchers to create a relatively gap-free mosaic, and high temporal resolution data or SAR data could also be used in regions that are particularly prone to heavy cloud cover.

Researchers can also examine studies that successfully mapped the same coffee production systems as those in the study area in question. Multiple studies, including Alves et al. [90], Bernardes et al. [44], and Gaertner et al. [88], mapped a general coffee class. Gomez et al. [91] concentrated just on shaded coffee, Schmitt-Harsh [7] and Schmitt-Harsh et al. [69] mapped coffee agroforests, and Kelley et al. [60] mapped rustic shaded coffee. A few studies we reviewed created multiple coffee classes to distinguish between coffee systems, however. Cordero-Sancho and Sader [45] mapped shaded coffee and sun coffee as two separate classes, Kawakubo and Machado [68] mapped three classes, production coffee, mixed coffee, and old/pruned coffee, and Ortega-Huerta et al. [55] distinguished open versus closed canopy. Widayati et al. [92] classified five systems that are present in Lampung Province, Indonesia (closed canopy cover ( $>50 \%$ cover), shade polyculture ( $25-50 \%$ cover), sun monoculture $(25-50 \%$ cover), sun coffee ( $25 \%$ cover), and newly planted (sparse cover) using an integrated pixel-based analysis and object-based approach, with an overall accuracy up to $85.4 \%$. Researchers should heavily weigh the efficacy of the approaches with multiple coffee classes into the decision to determine the best approach to develop scalable, replicable methodologies.

Researchers should develop a validation approach that emphasizes scalability and considers the accuracy assessment best practices identified by Olofsson et al. [95]. In the early stages of a study, researchers must create a robust sampling design to assess the accuracy, preferably based on 
stratified sampling to ensure a representative spatial distribution and accounting for the size of the study area, while identifying and integrating the limitations of the region of interest, such as study area accessibility/fieldwork cost and reference data availability. Olofsson et al. [95] also recommended that the reference dataset used in the response design should be a higher spatial resolution than the imagery used for the classification. In the absence of local independent validation data, many of the studies in this review used high-resolution optical imagery, such as WorldView 2 [88] and aerial photographs [69]. Analysts could use Light detection and ranging (LiDAR) data in conjunction with high-resolution imagery in agroforestry coffee systems. Campbell et al. [106] detailed and compared methods for understory density metrics and Jubanski et al. [107] presented methods for estimating understory density in Kalimantan, Indonesia. These studies detailed the natural variability observed in Indonesian forests and outlined the optimal configuration of sensors for accurate understory density estimation. Similar methods could be applied to validate the classification of shaded systems where a thick canopy obscures coffee plants. High-resolution satellite data, aerial photographs, and LiDAR data would significantly increase the project costs, therefore, limiting scalability. Liu et al. [81] instead used high-resolution imagery freely available on Google Earth as reference data. Similar methods using open source software, such as Collect Earth [108], have gained traction in recent years, and offer the opportunity to quickly, easily, and sustainably implement accuracy assessments in scalable classification methodologies.

\subsection{Future Research Directions}

In light of these considerations and the outcomes of the literature review, we can provide specific recommendations for researchers to incorporate into future coffee mapping studies. Object-based mapping approaches were deemed successful by the literature at many different scales $[47,88,93]$ and could represent a viable method. Widayati et al. [92] were able to use a pixel- and object-based hybrid approach to map five different production systems, which would be incredibly useful in a landscape with different levels of canopy coverage. Despite its uses, object-based methods are most effective with high-resolution data, which drastically increases the cost and limits scalability. As freely available data continues to increase in spatial resolution however, this could become more feasible. Spectral mixture methods, which can be implemented with moderate or low resolution data, could present a more practical scalable approach. These methods were limited in the literature, however, and need further exploration. The method that seems most promising, however, is an optical/SAR fusion method using Sentinel-1 and Sentinel-2. Similar optical/SAR fusion methods have been successfully implemented in the literature $[79,81,82]$, and although these studies mapped other commodities and forests, they could represent an effective solution for future global coffee mapping. These approaches fulfill many of the criteria outlined in the considerations section: the imagery is low cost at a relatively high resolution, the fusion strategy leverages the strengths of both sensors without being overwhelmingly complex, SAR data is not limited by cloud cover and can observe vegetation structure, and this method is applicable across many geographies, lending itself to be a replicable approach. Although fusion methods can be more laborious to implement, the imagery is readily available to analyze on platforms such as Google Earth Engine. Additionally, we recommend incorporating ancillary data into coffee classifications for any chosen method Many studies added DEM data $[60,81,82,89]$, forest cover maps [89], or precipitation and climatic data [60] to their models with great success.

Our review also highlights the sparsity of literature documenting remote sensing methods for mapping coffee systems. Determining the best methods and practices is inherently limited when numerous approaches have not been tested. Based on our results, we see gaps in the current research for researchers to address to fully actualize scalable, mapping methods for coffee systems. This includes the lack of research differentiating between production systems and the absence of important coffee-growing geographies. Fortunately, we see three recent advances as pivotal for advancing this space. First, the variety and availability of satellite constellations of high resolution and 
satellite sensors of moderate resolution improve the revisit rate, increasing the likelihood of cloud-free looks. Future research should more thoroughly explore Sentinel-2; its use, along with Landsat, represents the most practical resolution option to expand into new geographies and for large-scale coffee mapping. Second, recent investments in new sensors to measure ecosystem structure include SAR P-band and L-band SAR sensors [105], and space-borne Lidar (Global Ecosystem Dynamics Investigation (GEDI)) [109] may enable mapping and differentiation of complex shade coffee systems by measuring understory and canopy structures. Given the promising results from radar and multispectral sensor fusion approaches, particularly to map cacao systems, exploring the efficacy of these methods in mapping coffee extent is key for future research. This is an important literature gap since SAR data is not limited by cloud cover, a crucial advantage for mapping coffee-growing regions. Finally, advances in cloud computing and deep learning algorithms can improve classification in complex landscapes [110]. Deep learning has been successfully used in recent studies to support analyses of image fusion, LCLUC, object detection, and scene recognition, among others [111]. By stressing these research opportunities, we hope researchers can focus on the specific urgent needs for coffee mapping to inform global investments in coffee production communities to improve livelihoods, support biodiversity conservation, reduce deforestation, and improve sustainable production.

\section{Conclusions}

Routine mapping of coffee systems remains a critical need to understand how coffee drives landscape dynamics and, thus, develop pathways to ensure that coffee is a sustainably produced global commodity. Our literature review highlights the variety of approaches and sensors that researchers have previously employed to accurately map coffee, to inform future coffee mapping studies on the most effective methods for replicable mapping of diverse coffee systems. The most common methods were pixel-based methods for classifying both high- and moderate-resolution optical imagery. We did not identify any routine methods that produced consistently accurate results, thus making a specific method recommendation challenging. We also found significant gaps in the literature, including mapping coffee using other sensor types, such as SAR, studies differentiating between multiple production systems, and the scant published literature on mapping coffee in geographies vital to coffee production, such as Vietnam and Ethiopia. Therefore, we use the results of our literature to recommend the following considerations for choosing a method for future coffee mapping studies: minimizing the cost of imagery, balancing the accuracy of a method with the complexity of the analysis, identifying methods that have been applied successfully in similar landscapes and production systems, and planning the accuracy assessment at the start of the project based on best practices and resources available. While researchers can apply these considerations to any remote sensing mapping study, cost-effective, simple analyses are especially crucial for coffee mapping given the importance of developing replicable and scalable methods to produce large-scale coffee classifications that contribute towards sustainability efforts. In addition, mapping coffee extent given the complex landscape characteristics of coffee systems and heterogeneity of production systems requires deliberate evaluations of remote sensing methodological choices for successful mapping. Given these considerations, our study found that object-based and sub pixel-based methods effectively balanced complexity and accuracy; however, object-based methods are most effective with expensive high-resolution imagery, and sub pixel-based methods were limited in the literature. Another highly promising method is a Sentinel-1/Sentinel-2 fusion approach. While this was not used to map coffee in the literature, it was successfully implemented to map cacao, and it fulfills many of the considerations listed above. Most importantly, future research needs to address the significant gaps in the literature highlighted in this review to gain a complete understanding of coffee mapping using remote sensing. The increasing number of satellite constellations and data availability, notably SAR, as well as the recent, increasing accessibility to cloud computing, provides an opportunity to further support this endeavor by facilitating broadscale and robust coffee mapping projects contributing to efforts towards sector-wide sustainability. 
Supplementary Materials: The following are available online at http://www.mdpi.com/2072-4292/12/12/2041/s1, Table S1: Classification Methods from the Literature, Table S2: Considerations for Choosing the Best Method, Table S3: Validation Methods from the Literature.

Author Contributions: Conceptualization, K.T., J.H.H. and M.A.W.; Funding acquisition, K.T., J.H.H. and M.A.W.; Investigation, D.A.H., K.T., J.H.H., M.A.W., L.R., K.K., M.S.-H. and L.C.K.; Project Administration, D.A.H., K.T. and M.A.W.; Visualization, D.A.H., K.T., J.H.H., M.A.W., L.R. and K.K.; Writing-Original draft preparation, D.A.H., K.T., J.H.H., M.A.W. and K.K.; Writing-Review and editing, D.A.H., K.T., J.H.H., M.A.W., L.R., K.K., M.S.-H., L.C.K. and F.F. All authors have read and agreed to the published version of the manuscript.

Funding: This research was funded by the Walmart Foundation, Request ID 38454983.

Acknowledgments: The authors would like to thank Richard Anderson for providing additional literature, Christian Bunn for revising the manuscript, and Bambi Semroc, Dora Samaniego, and Lorena Bustos for their leadership and support. The authors would also like to thank additional participants of the Walmart Foundation coffee mapping project workshop for their intellectual contribution to this work including Marecelo Herowitz, David Hughell, Jawoo Koo, Kevin Ocampo, Ahsan Rabbani, Anurag Ramachandra, Christy Melhart Slay, Henriette Walz, and Liangzhi You.

Conflicts of Interest: The authors declare no conflict of interest.

\section{References}

1. Goldschein, E. 11 incredible facts about the global coffee industry. Bus. Insider 2011. Available online: https://www.businessinsider.com/facts-about-the-coffee-industry-2011-11 (accessed on 6 June 2020).

2. Illy, E. The complexity of coffee. Sci. Am. 2002, 286, 86-91. [CrossRef] [PubMed]

3. International Trade Centre UNCTAD/WTO. The Coffee Exporter's Guide, 3rd ed.; International Trade Centre UNCTAD/WTO: Geneva, Switzerland, 2011.

4. Sustainable Coffee Challenge. Resources. Available online: https://www.sustaincoffee.org/resources/ (accessed on 6 June 2020).

5. Consumer Goods Forum. Commitments \& Achievements. Available online: https://www. theconsumergoodsforum.com/initiatives/environmental-sustainability/about/our-commitments+and+ achievements (accessed on 6 June 2020).

6. New York Declaration on Forests; UN Climate Summit, United Nations Headquarters: New York, NY, USA, 2014.

7. Schmitt-Harsh, M. Landscape change in Guatemala: Driving forces of forest and coffee agroforest expansion and contraction from 1990 to 2010. Appl. Geogr. 2013, 40, 40-50. [CrossRef]

8. Bray, D. Forest cover dynamics and forest transitions in Mexico and Central America: Towards a "Great Restoration"? In Reforesting Landscapes; Springer: Dordrecht, The Netherlands, 2009; Volume 10, pp. 85-120, ISBN 978-1-4020-9656-3.

9. Soto-Pinto, L.; Anzueto, M.; Mendoza, J.; Ferrer, G.J.; de Jong, B. Carbon sequestration through agroforestry in indigenous communities of Chiapas, Mexico. Agrofor. Syst. 2009, 78, 39-51. [CrossRef]

10. Van Noordwijk, M.; Rahayu, S.; Hairiah, K.; Wulan, Y.; Farida, A.; Verbist, B. Carbon stock assessment for a forest-to-coffee conversion landscape in Sumber-Jaya (Lampung, Indonesia): From allometric equations to land use change analysis. Sci. China 2002, 45, 75-86.

11. Bliss, S. Coffee biomes. Geogr. Bull. 2017, 49, 29.

12. Bunn, C.; Laderach, P.; Ovalle Rivera, O.; Kirschke, D. A bitter cup: Climate change profile of global production of Arabica and Robusta coffee. Clim. Chang. 2014, 129. [CrossRef]

13. Vaast, P.; Harmand, J.-M.; Rapidel, B.; Jagoret, P.; Deheuvels, O. Coffee and cocoa production in agroforestry-A climate-smart agriculture model. In Climate Change and Agriculture Worldwide; Torquebiau, E., Ed.; Springer: Dordrecht, The Netherlands, 2016; pp. 209-224, ISBN 978-94-017-7462-8.

14. Jha, S.; Bacon, C.M.; Philpott, S.M.; Rice, R.A.; Méndez, V.E.; Läderach, P. A review of ecosystem services, farmer livelihoods, and value chains in shade coffee agroecosystems. In Integrating Agriculture, Conservation and Ecotourism: Examples from the Field; Issues in Agroecology-Present Status and Future Prospectus; Campbell, W.B., Lopez Ortiz, S., Eds.; Springer: Dordrecht, The Netherlands, 2011; pp. 141-208, ISBN 978-94-007-1309-3.

15. Vignola, R.; Harvey, C.A.; Bautista-Solis, P.; Avelino, J.; Rapidel, B.; Donatti, C.; Martinez, R. Ecosystem-based adaptation for smallholder farmers: Definitions, opportunities and constraints. Agric. Ecosyst. Environ. 2015, 211, 126-132. [CrossRef] 
16. Food and Agriculture Organization of the United Nations. FAOSTAT Statistical Database. Available online: http://www.fao.org/faostat/en/\#data (accessed on 6 June 2020).

17. DaMatta, F.M.; Ronchi, C.P.; Maestri, M.; Barros, R.S. Ecophysiology of coffee growth and production. Braz. J. Plant Physiol. 2007, 19, 485-510. [CrossRef]

18. Waller, J.M.; Bigger, M.; Hillocks, R.J. Coffee Pests, Diseases and Their Management, 1st ed.; CABI: Wallingford, UK; Cambridge, MA, USA, 2007; ISBN 978-1-84593-129-2.

19. Philpott, S.M.; Arendt, W.J.; Armbrecht, I.; Bichier, P.; Diestch, T.V.; Gordon, C.; Greenberg, R.; Perfecto, I.; Reynoso-Santos, R.; Soto-Pinto, L.; et al. Biodiversity loss in Latin American coffee landscapes: Review of the evidence on ants, birds, and trees. Conserv. Biol. 2008, 22, 1093-1105. [CrossRef]

20. Kremen, C.; Iles, A.; Bacon, C. Diversified farming systems: An agroecological, systems-based alternative to modern industrial agriculture. Ecol. Soc. 2012, 17. [CrossRef]

21. Perfecto, I.; Mas, A.; Dietsch, T.; Vandermeer, J. Conservation of biodiversity in coffee agroecosystems: A tri-taxa comparison in southern Mexico. Biodivers. Conserv. 2003, 12, 1239-1252. [CrossRef]

22. Perfecto, I.; Vandermeer, J.; Mas, A.; Pinto, L.S. Biodiversity, yield, and shade coffee certification. Ecol. Econ. 2005, 54, 435-446. [CrossRef]

23. Schmitt-Harsh, M.; Evans, T.P.; Castellanos, E.; Randolph, J.C. Carbon stocks in coffee agroforests and mixed dry tropical forests in the western highlands of Guatemala. Agrofor. Syst. 2012, 86, 141-157. [CrossRef]

24. Sekercioglu, C.H.; Loarie, S.R.; Oviedo Brenes, F.; Ehrlich, P.R.; Daily, G.C. Persistence of forest birds in the Costa Rican agricultural countryside. Conserv. Biol. 2007, 21, 482-494. [CrossRef]

25. Vandermeer, J.; Perfecto, I.; Philpott, S. Ecological complexity and pest control in organic coffee production: Uncovering an autonomous ecosystem service. BioScience 2010, 60, 527-537. [CrossRef]

26. Karp, D.S.; Mendenhall, C.D.; Sandí, R.F.; Chaumont, N.; Ehrlich, P.R.; Hadly, E.A.; Daily, G.C. Forest bolsters bird abundance, pest control and coffee yield. Ecol. Lett. 2013, 16, 1339-1347. [CrossRef]

27. Jha, S.; Bacon, C.M.; Philpott, S.M.; Ernesto Méndez, V.; Läderach, P.; Rice, R.A. Shade coffee: Update on a disappearing refuge for biodiversity. BioScience 2014, 64, 416-428. [CrossRef]

28. Gobbi, J.A. Is biodiversity-friendly coffee financially viable? An analysis of five different coffee production systems in western El Salvador. Ecol. Econ. 2000, 33, 267-281. [CrossRef]

29. Philpott, S.M.; Dietsch, T. Coffee and conservation: A global context and the value of farmer involvement. Conserv. Biol. 2003, 17, 1844-1846. [CrossRef]

30. Richards, M.B.; Méndez, V.E. Interactions between carbon sequestration and shade tree diversity in a smallholder coffee cooperative in El Salvador. Conserv. Biol. 2014, 28, 489-497. [CrossRef] [PubMed]

31. Lin, B.B. Resilience in agriculture through crop diversification: Adaptive management for environmental change. BioScience 2011, 61, 183-193. [CrossRef]

32. Borkhataria, R.; Collazo, J.A.; Groom, M.J.; Jordan-Garcia, A. Shade-grown coffee in Puerto Rico: Opportunities to preserve biodiversity while reinvigorating a struggling agricultural commodity. Agric. Ecosyst. Environ. 2012, 149, 164-170. [CrossRef]

33. Perfecto, I.; Rice, R.A.; Greenberg, R.; Van der Voort, M.E. Shade coffee: A disappearing refuge for biodiversity. BioScience 1996, 46, 598-608. [CrossRef]

34. Moguel, P.; Toledo, V.M. Biodiversity conservation in traditional coffee systems of Mexico. Conserv. Biol. 1999, 13, 11-21. [CrossRef]

35. Faminow, M.D. Biodiversity of Flora and Fauna in Shaded Coffee Systems; International Centre for Research in Agroforestry Latin American Regional Office: Lima, Peru, 2001; p. 43.

36. Moreira, M.A.; Rudorff, B.F.T.; Barros, M.A.; de Faria, V.G.C.; Adami, M. Geotecnologias para mapear lavouras de café nos estados de Minas Gerais e São Paulo. Eng. Agríc. 2010, 30, 1123-1135. [CrossRef]

37. Jaffee, D. Brewing Justice: Fair Trade Coffee, Sustainability, and Survival, 1st ed.; University of California Press: Oakland, CA, USA, 2007; ISBN 978-0-520-24958-5.

38. Somarriba, E.; Harvey, C.; Samper, M.; Anthony, F.; Gonzalez, J.; Staver, C.; Rice, R. Biodiversity conservation in neotropical coffee (Coffea arabica) plantations. In Agroforestry and Biodiversity Conservation in Tropical Landscapes; Springer: Dordrecht, The Netherlands, 2004; pp. 198-226.

39. Soto-Pinto, L.; Villalvazo-López, V.; Jiménez-Ferrer, G.; Ramírez-Marcial, N.; Montoya, G.; Sinclair, F.L. The role of local knowledge in determining shade composition of multistrata coffee systems in Chiapas, Mexico. Biodivers. Conserv. 2007, 16, 419-436. [CrossRef] 
40. Tabor, K.; Hewson, J. The evolution of remote sensing applications vital to effective biodiversity conservation and sustainable development. In Satellite Remote Sensing for Conservation Action: Case Studies from Aquatic and Terrestrial Ecosystems; Leidner, A.K., Buchanan, G.M., Eds.; Cambridge University Press: Cambridge, UK, 2018; pp. 274-300, ISBN 978-1-316-51386-6.

41. Woodcock, C.E.; Allen, R.; Anderson, M.; Belward, A.; Bindschadler, R.; Cohen, W.; Gao, F.; Goward, S.N.; Helder, D.; Helmer, E.; et al. Free access to Landsat imagery. Science 2008, 320, 1011. [CrossRef]

42. Wulder, M.A.; Loveland, T.R.; Roy, D.P.; Crawford, C.J.; Masek, J.G.; Woodcock, C.E.; Allen, R.G.; Anderson, M.C.; Belward, A.S.; Cohen, W.B.; et al. Current status of Landsat program, science, and applications. Remote Sens. Environ. 2019, 225, 127-147. [CrossRef]

43. Langford, M.; Bell, W. Land cover mapping in a tropical hillsides environment: A case study in the Cauca region of Colombia. Int. J. Remote Sens. 1997, 18, 1289-1306. [CrossRef]

44. Bernardes, T.; Moreira, M.A.; Adami, M.; Giarolla, A.; Rudorff, B.F.T. Monitoring biennial bearing effect on coffee yield using MODIS remote sensing imagery. Remote Sens. 2012, 4, 2492-2509. [CrossRef]

45. Cordero-Sancho, S.; Sader, S.A. Spectral analysis and classification accuracy of coffee crops using Landsat and a topographic-environmental model. Int. J. Remote Sens. 2007, 28, 1577-1593. [CrossRef]

46. Lu, D.; Batistella, M.; de Miranda, E.E.; Moran, E. A comparative study of Landsat TM and SPOT HRG images for vegetation classification in the Brazilian Amazon. Photogramm. Eng. Remote Sens. 2008, 74, 311-321. [CrossRef] [PubMed]

47. Bolanos, S. Using Image Analysis and GIS for Coffee Mapping; Department of Geography, McGill University: Montréal, QC, Canada, 2007.

48. Kushalappa, A.C.; Eskes, A.B. Coffee Rust: Epidemiology, Resistance, and Management; CRC Press: Boca Raton, FL, USA, 1989; ISBN 978-0-8493-6899-8.

49. Finer, M.; Novoa, S.; Weisse, M.J.; Petersen, R.; Mascaro, J.; Souto, T.; Stearns, F.; Martinez, R.G. Combating deforestation: From satellite to intervention. Science 2018, 360, 1303-1305. [CrossRef]

50. Reiche, J.; Lucas, R.; Mitchell, A.L.; Verbesselt, J.; Hoekman, D.H.; Haarpaintner, J.; Kellndorfer, J.M.; Rosenqvist, A.; Lehmann, E.A.; Woodcock, C.E.; et al. Combining satellite data for better tropical forest monitoring. Nat. Clim. Chang. 2016, 6, 120-122. [CrossRef]

51. Planet Our Constellations. Available online: https://storage.googleapis.com/planet-ditl/day-in-the-life/index. html (accessed on 6 June 2020).

52. Li, J.; Roy, D.P. A global analysis of Sentinel-2A, Sentinel-2B and Landsat-8 data revisit intervals and implications for terrestrial monitoring. Remote Sens. 2017, 9, 902. [CrossRef]

53. Pullin, A.S.; Stewart, G.B. Guidelines for systematic review in conservation and environmental management. Conserv. Biol. 2006, 20, 1647-1656. [CrossRef]

54. Maurice, N.E.; Davis, J. Unraveling the Underlying Causes of Price Volatility in World Coffee and Cocoa Commodity Markets; Erasmus University: Rotterdam, The Netherlands, 2011.

55. Ortega-Huerta, M.A.; Komar, O.; Price, K.P.; Ventura, H.J. Mapping coffee plantations with Landsat imagery: An example from El Salvador. Int. J. Remote Sens. 2012, 33, 220-242. [CrossRef]

56. Martínez-Verduzco, G.C.; Galeana-Pizaña, J.M.; Cruz-Bello, G.M. Coupling community mapping and supervised classification to discriminate shade coffee from natural vegetation. Appl. Geogr. 2012, 34, 1-9. [CrossRef]

57. Tutu Benefoh, D.; Villamor, G.B.; van Noordwijk, M.; Borgemeister, C.; Asante, W.A.; Asubonteng, K.O. Assessing land-use typologies and change intensities in a structurally complex Ghanaian cocoa landscape. Appl. Geogr. 2018, 99, 109-119. [CrossRef]

58. Bourgoin, C.; Oszwald, J.; Bourgoin, J.; Gond, V.; Blanc, L.; Dessard, H.; Phan, T.V.; Sist, P.; Läderach, P.; Reymondin, L. Assessing the ecological vulnerability of forest landscape to agricultural frontier expansion in the Central Highlands of Vietnam. Int. J. Appl. Earth Obs. Geoinf. 2020, 84, 101958. [CrossRef]

59. Chemura, A.; Mutanga, O. Developing detailed age-specific thematic maps for coffee (Coffea arabica L.) in heterogeneous agricultural landscapes using random forests applied on Landsat 8 multispectral sensor. Geocarto Int. 2017, 32, 759-776. [CrossRef]

60. Kelley, L.C.; Pitcher, L.; Bacon, C. Using Google Earth Engine to map complex shade-grown coffee landscapes in northern Nicaragua. Remote Sens. 2018, 10, 952. [CrossRef] 
61. Baeta, R.; Nogueira, K.; Menotti, D.; dos Santos, J.A. Learning deep features on multiple scales for coffee crop recognition. In Proceedings of the 2017 30th SIBGRAPI Conference on Graphics, Patterns and Images (SIBGRAPI), Niteroi, Brazil, 17-20 October 2017; pp. 262-268.

62. Ramirez, G.M.; Zullo Junior, J.; Assad, E.D.; Pinto, H.S. Comparação de dados dos satélites Ikonos-II e Landsat/ETM+ no estudo de áreas cafeeiras [Comparison between Ikonos-II and Landsat/ETM+ satellites data in the study of coffee areas]. Pesq. Agropec. Bras. 2006, 41, 661-666. [CrossRef]

63. Sánchez-Méndez, A.G.; Arguijo-Hernández, S.P. Análisis de imágenes multiespectrales para la detección de cultivos y detección de plagas y enfermedades en la producción de café [Analysis of multispectral images for the detection of crops and detection of pests and diseases in coffee production]. RCS 2018, 147, 309-317. [CrossRef]

64. Moreira, M.A.; Adami, M.; Rudorff, B.F.T. Análise espectral e temporal da cultura do café em imagens Landsat [Spectral and temporal behavior analysis of coffee crop in Landsat images]. Pesqui. Agropecu. Bras. 2004, 39, 223-231. [CrossRef]

65. Chemura, A.; Mutanga, O.; Dube, T. Integrating age in the detection and mapping of incongruous patches in coffee (Coffea arabica) plantations using multi-temporal Landsat 8 NDVI anomalies. Int. J. Appl. Earth Obs. Geoinf. 2017, 57, 1-13. [CrossRef]

66. González, F.A.; Gómez, J.J.; Amaya, D.F. Multispectral image processing in coffee and cocoa crops. Rev. CINTEX 2017, 22, 51-67. [CrossRef]

67. Johl, R.; Henke, S.; Schweikart, J. Acquiring geodata for coffee mapping using remote sensing data based on a pilot study in the Mbinga district Tanzania. Zent. für Geol. Paläontologie Teil I 2014, 2014, 211-225. [CrossRef]

68. Kawakubo, F.S.; Machado, R.P.P. Mapping coffee crops in southeastern Brazil using spectral mixture analysis and data mining classification. Int. J. Remote Sens. 2016, 37, 3414-3436. [CrossRef]

69. Schmitt-Harsh, M.; Sweeney, S.P.; Evans, T. Classification of Coffee-Forest Landscapes Using Landsat TM Imagery and Spectral Mixture Analysis. Photogramm. Eng. Remote. Sens. 2013, 79, 457-468. [CrossRef]

70. Bispo, R.C.; Lamparelli, R.A.C.; Rocha, J.V. Using fraction images derived from modis data for coffee crop mapping. Eng. Agríc. 2014, 34, 102-111. [CrossRef]

71. Lu, D.; Moran, E.; Batistella, M. Linear mixture model applied to Amazonian vegetation classification. Remote Sens. Environ. 2003, 87, 456-469. [CrossRef]

72. Lu, D.; Batistella, M.; Moran, E.; Mausel, P. Application of spectral mixture analysis to Amazonian land-use and land-cover classification. Int. J. Remote Sens. 2004, 25, 5345-5358. [CrossRef]

73. Souza, J.; Siqueira, J.V.; Sales, M.H.; Fonseca, A.V.; Ribeiro, J.G.; Numata, I.; Cochrane, M.A.; Barber, C.P.; Roberts, D.A.; Barlow, J. Ten-Year Landsat classification of deforestation and forest degradation in the Brazilian Amazon. Remote Sens. 2013, 5, 5493-5513. [CrossRef]

74. Lelong, C.C.D.; Thong-Chane, A. Application of textural analysis on very high resolution panchromatic images to map coffee orchards in Uganda. In Proceedings of the IGARSS 2003. 2003 IEEE International Geoscience and Remote Sensing Symposium. Proceedings (IEEE Cat. No.03CH37477), Toulouse, France, 21-25 July 2003; Volume 2, pp. 1007-1009.

75. Dostálová, A.; Hollaus, M.; Milenković, M.; Wagner, W. Forest area derivation from Sentinel-1 data. ISPRS Ann. Photogramm. Remote Sens. Spat. Inf. Sci. 2016, III-7, 227-233. [CrossRef]

76. Silva, W.F.; Rudorff, B.F.T.; Formaggio, A.R.; Paradella, W.R.; Mura, J.C. Discrimination of agricultural crops in a tropical semi-arid region of Brazil based on L-band polarimetric airborne SAR data. ISPRS J. Photogramm. Remote Sens. 2009, 64, 458-463. [CrossRef]

77. Otsu, N. A threshold selection method from gray-level histograms. IEEE Trans. Syst. Man Cybern. 1979, 9, 62-66. [CrossRef]

78. Hartigan, J.A.; Wong, M.A. Algorithm AS 136: A k-means clustering algorithm. J. R. Stat. Soc. Ser. C (Appl. Stat.) 1979, 28, 100-108. [CrossRef]

79. Zhou, T.; Pan, J.; Zhang, P.; Wei, S.; Han, T. Mapping winter wheat with multi-temporal SAR and optical images in an urban agricultural region. Sensors 2017, 17, 1210. [CrossRef]

80. Lu, D.; Batistella, M.; Moran, E. Land-cover classification in the Brazilian Amazon with the integration of Landsat ETM+ and Radarsat data. Int. J. Remote Sens. 2007, 28, 5447-5459. [CrossRef]

81. Liu, Y.; Gong, W.; Hu, X.; Gong, J. Forest type identification with random forest using Sentinel-1A, Sentinel-2A, multi-temporal Landsat-8 and DEM data. Remote Sens. 2018, 10, 946. [CrossRef] 
82. Numbisi, F.N.; Van Coillie, F.M.B.; De Wulf, R. Delineation of cocoa agroforests using multiseason Sentinel-1 SAR images: A low grey level range reduces uncertainties in GLCM texture-based mapping. ISPRS Int. J. Geo-Inf. 2019, 8, 179. [CrossRef]

83. Fagan, M.E.; DeFries, R.S.; Sesnie, S.E.; Arroyo-Mora, J.P.; Soto, C.; Singh, A.; Townsend, P.A.; Chazdon, R.L. Mapping species composition of forests and tree plantations in northeastern Costa Rica with an integration of hyperspectral and multitemporal Landsat imagery. Remote Sens. 2015, 7, 5660-5696. [CrossRef]

84. Lelong, C. Very High Resolution Satellite-Imagery-Based Agrosystems Mapping: To Help Defining Geographic Indications for the Arabica Coffee in the Kintamani Country of Bali; CIRAD-AMIS: Montpellier, France, 2005.

85. Vieira, T.G.C.; Alves, H.M.R.; Bertoldo, M.A.; Souza, V.C.O. de Geotecnologias na avaliação das mudanças no uso da terra de regiões cafeeiras do estado de Minas Gerais, Brasil [Geotechnologies in the assessment of land use changes in coffee regions of the state of Minas Gerais in Brazil]. Coffee Sci. 2007, 2, 142-149. [CrossRef]

86. Dos Santos, J.A.; Gosselin, P.-H.; Philipp-Foliguet, S.; Da Silva Torres, R.; Falcao, A.X. Multiscale classification of remote sensing images. IEEE Trans. Geosci. Remote Sens. 2012, 50, 3764-3775. [CrossRef]

87. Schapire, R.E. A brief introduction to boosting. In Proceedings of the Sixteenth International Joint Conference on Artificial Intelligence; Morgan Kaufmann Publishers Inc.: San Francisco, CA, USA, 1999; Volume 2, pp. 1401-1406.

88. Gaertner, J.; Genovese, V.B.; Potter, C.; Sewake, K.; Manoukis, N.C. Vegetation classification of Coffea on Hawaii Island using WorldView-2 satellite imagery. JARS 2017, 11, 046005. [CrossRef]

89. Mukashema, A.; Veldkamp, A.; Vrieling, A. Automated high resolution mapping of coffee in Rwanda using an expert Bayesian network. Int. J. Appl. Earth Obs. Geoinf. 2014, 33, 331-340. [CrossRef]

90. Alves, H.M.R.; Vieira, T.G.C.; Volpato, M.M.L.; Lacerda, M.P.C.; Borém, F.M. Geotechnologies for the characterization of specialty coffee environments of Mantiqueira de Minas In Brazil. Int. Arch. Photogramm. Remote Sens. Spat. Inf. Sci. 2016, XLI-B8, 797-799. [CrossRef]

91. Gomez, C.; Mangeas, M.; Petit, M.; Corbane, C.; Hamon, P.; Hamon, S.; De Kochko, A.; Pierres, D.; Poncet, V.; Despinoy, M. Use of high-resolution satellite imagery in an integrated model to predict the distribution of shade coffee tree hybrid zones. Remote Sens. Environ. 2010, 114, 2731-2744. [CrossRef]

92. Widayati, A.; Verbist, B.; Meijerink, A. Application of Combined Pixel-Based and Spatial-Based Approaches for Improved Mixed Vegetation. 2003. Available online: https://www.researchgate.net/publication/ 2552065_Application_Of_Combined_Pixel-Based_And_Spatial-Based_Approaches_For_Improved_ Mixed_Vegetation (accessed on 6 June 2020).

93. Xiong, J.; Thenkabail, P.S.; Tilton, J.C.; Gumma, M.K.; Teluguntla, P.; Oliphant, A.; Congalton, R.G.; Yadav, K.; Gorelick, N. Nominal 30-m cropland extent map of continental Africa by integrating pixel-based and object-based algorithms using Sentinel-2 and Landsat-8 data on Google Earth Engine. Remote Sens. 2017, 9 , 1065. [CrossRef]

94. Dos Santos, J.A.; Faria, F.; Calumby, R.; Torres, R.D.S.; Lamparelli, R.A.C. A Genetic Programming approach for coffee crop recognition. In Proceedings of the 2010 IEEE International Geoscience and Remote Sensing Symposium, Honolulu, HI, USA, 25-30 July 2010; pp. 3418-3421.

95. Olofsson, P.; Foody, G.M.; Herold, M.; Stehman, S.V.; Woodcock, C.E.; Wulder, M.A. Good practices for estimating area and assessing accuracy of land change. Remote Sens. Environ. 2014, 148, 42-57. [CrossRef]

96. Cohen, J. A Coefficient of Agreement for Nominal Scales. Educ. Psychol. Meas. 2016. [CrossRef]

97. Fawcett, T. Introduction to ROC analysis. Pattern Recognit. Lett. 2006, 27, 861-874. [CrossRef]

98. Chemura, A.; Mutanga, O.; Dube, T. Separability of coffee leaf rust infection levels with machine learning methods at Sentinel-2 MSI spectral resolutions. Precis. Agric. 2017, 18, 859-881. [CrossRef]

99. Chemura, A.; Mutanga, O.; Odindi, J.; Kutywayo, D. Mapping spatial variability of foliar nitrogen in coffee (Coffea arabica L.) plantations with multispectral Sentinel-2 MSI data. ISPRS J. Photogramm. Remote Sens. 2018, 138. [CrossRef]

100. Belgiu, M.; Csillik, O. Sentinel-2 cropland mapping using pixel-based and object-based time-weighted dynamic time warping analysis. Remote Sens. Environ. 2018, 204, 509-523. [CrossRef]

101. Radoux, J.; Chomé, G.; Jacques, D.C.; Waldner, F.; Bellemans, N.; Matton, N.; Lamarche, C.; D’Andrimont, R.; Defourny, P. Sentinel-2's Potential for Sub-Pixel Landscape Feature Detection. Remote Sens. 2016, 8, 488. [CrossRef]

102. Claverie, M.; Ju, J.; Masek, J.G.; Dungan, J.L.; Vermote, E.F.; Roger, J.-C.; Skakun, S.V.; Justice, C. The Harmonized Landsat and Sentinel-2 surface reflectance data set. Remote Sens. Environ. 2018, 219, 145-161. [CrossRef] 
103. Lillesand, T.; Kiefer, R.W.; Chipman, J. Remote Sensing and Image Interpretation, 7th ed.; Wiley: Hoboken, NJ, USA, 2015.

104. Ovalle-Rivera, O.; Läderach, P.; Bunn, C.; Obersteiner, M.; Schroth, G. Projected shifts in Coffea arabica suitability among major global producing regions due to climate change. PLoS ONE 2015, 10, e0124155. [CrossRef]

105. Joshi, N.; Baumann, M.; Ehammer, A.; Fensholt, R.; Grogan, K.; Hostert, P.; Jepsen, M.R.; Kuemmerle, T.; Meyfroidt, P.; Mitchard, E.T.A.; et al. A review of the application of optical and radar remote sensing data fusion to land use mapping and monitoring. Remote Sens. 2016, 8, 70. [CrossRef]

106. Campbell, M.J.; Dennison, P.E.; Hudak, A.T.; Parham, L.M.; Butler, B.W. Quantifying understory vegetation density using small-footprint airborne lidar. Remote Sens. Environ. 2018, 215, 330-342. [CrossRef]

107. Jubanski, J.; Ballhorn, U.; Kronseder, K.; Franke, J.; Siegert, F. Detection of large above-ground biomass variability in lowland forest ecosystems by airborne LiDAR. Biogeosciences 2013, 10, 3917-3930. [CrossRef]

108. Bey, A.; Sánchez-Paus Díaz, A.; Maniatis, D.; Marchi, G.; Mollicone, D.; Ricci, S.; Bastin, J.-F.; Moore, R.; Federici, S.; Rezende, M.; et al. Collect Earth: Land use and land cover assessment through augmented visual interpretation. Remote Sens. 2016, 8, 807. [CrossRef]

109. Duncanson, L.; Armston, J.; Disney, M.; Avitabile, V.; Barbier, N.; Calders, K.; Carter, S.; Chave, J.; Herold, M.; Crowther, T.W.; et al. The Importance of Consistent Global Forest Aboveground Biomass Product Validation. Surv. Geophys. 2019, 40, 979-999. [CrossRef]

110. Cheng, G.; Yang, C.; Yao, X.; Guo, L.; Han, J. When Deep Learning Meets Metric Learning: Remote Sensing Image Scene Classification via Learning Discriminative CNNs. IEEE Trans. Geosci. Remote Sens. 2018, 56, 2811-2821. [CrossRef]

111. Ma, L.; Liu, Y.; Zhang, X.; Ye, Y.; Yin, G.; Johnson, B.A. Deep learning in remote sensing applications: A meta-analysis and review. ISPRS J. Photogramm. Remote Sens. 2019, 152, 166-177. [CrossRef]

(C) 2020 by the authors. Licensee MDPI, Basel, Switzerland. This article is an open access article distributed under the terms and conditions of the Creative Commons Attribution (CC BY) license (http://creativecommons.org/licenses/by/4.0/). 